\title{
Perisaccadic Perception of Visual Space in People with Schizophrenia
}

\author{
Alby Richard, ${ }^{1 \star}$ Jan Churan, ${ }^{1 \star}$ Veronica Whitford, ${ }^{2}$ Gillian A. 0’Driscoll, ${ }^{2}$ Debra Titone, ${ }^{2}$ and Christopher C. Pack ${ }^{1}$ \\ ${ }^{1}$ Department of Neurology and Neurosurgery, Montreal Neurological Institute, McGill University, Montreal, Quebec H3A 2B4, Canada, and ${ }^{2}$ Department of \\ Psychology, McGill University, Montreal, Quebec H3A 1B1, Canada
}

\begin{abstract}
Corollary discharge signals are found in the nervous systems of many animals, where they serve a large variety of functions related to the integration of sensory and motor signals. In humans, an important corollary discharge signal is generated by oculomotor structures and communicated to sensory systems in concert with the execution of each saccade. This signal is thought to serve a number of purposes related to the maintenance of accurate visual perception. The properties of the oculomotor corollary discharge can be probed by asking subjects to localize stimuli that are flashed briefly around the time of a saccade. The results of such experiments typically reveal large errors in localization. Here, we have exploited these well-known psychophysical effects to assess the potential dysfunction of corollary discharge signals in people with schizophrenia. In a standard perisaccadic localization task, we found that, compared with controls, patients with schizophrenia exhibited larger errors in localizing visual stimuli. The pattern of errors could be modeled as an overdamped corollary discharge signal that encodes instantaneous eye position. The dynamics of this signal predicted symptom severity among patients, suggesting a possible mechanistic basis for widely observed behavioral manifestations of schizophrenia.
\end{abstract}

Key words: corollary discharge; oculomotor; perception; saccades; schizophrenia; vision

\section{Introduction}

The nervous system constantly monitors the consequences of its own actions. In many species, this process is associated with signals that are sent from motor structures to sensory brain regions. These corollary discharges (CDs) can be used to assess the accuracy of ongoing movements or to adjust sensory signals that occur in concert with a movement (Crapse and Sommer, 2008).

In primates, there are well-known CD pathways that communicate information related to the metrics of saccadic eye movements (Schlag and Schlag-Rey, 1984; Sommer and Wurtz, 2004). Because primates execute several saccades each second, these CD signals are thought to be essential for accurate visual perception. However, under certain laboratory conditions, they can cause significant distortions in the perception of visual space (Ross et al., 1997; Lappe et al., 2000). Specifically, when an object is flashed briefly before or during a saccade, subjects make substantial errors in estimating its position. These errors are of two main types: a compression of visual space, whereby the objects appear closer to the saccade target (ST) than they really are; and a shift in

Received Nov. 6, 2013; revised Feb. 11, 2014; accepted Feb. 21, 2014.

Author contributions: J.C. and C.C.P. designed research; V.W., G.A.O., and D.T. performed research; A.R., J.C., and C.C.P. analyzed data; A.R. and C.C.P. wrote the paper.

This work was supported by Natural Sciences and Engineering Research Council Grant 341534-12, the National Alliance for Research on Schizophrenia and Depression, the EJLB Foundation to C.C.P., Natural Sciences and Engineering Research Council Grant 204609 to D.T., and an Natural Sciences and Engineering Research Council postgraduate scholarship to V.W.

The authors declare no competing financial interests.

${ }^{*}$ A.R. and J.C. contributed equally to this work.

Correspondence should be addressed to Dr. Christopher C. Pack, Montreal Neurological Institute, Room 786, 3801 University Street, Montreal, Quebec H3A 2B4, Canada. E-mail: christopher.pack@mcgill.ca.

DOI:10.1523/JNEUROSCI.4744-13.2014

Copyright $\odot 2014$ the authors $\quad 0270-6474 / 14 / 344760-06 \$ 15.00 / 0$ the visual representation, whereby objects appear to be displaced along the saccade trajectory. The shift and compression effects may be the result of different CD signals.

The importance of CDs has been highlighted in recent work indicating that an impairment of these signals can account for some of the positive symptoms of certain psychiatric disorders (Feinberg, 1978). In schizophrenia, a defective CD has been hypothesized as the neural basis for anomalous perception in audition (Ford et al., 2002; Ford et al., 2004), somatosensation (Blakemore et al., 1998; Shergill et al., 2005, 2014), and vision (Lindner et al., 2005; Spering et al., 2013). These findings, along with data from anatomical studies, support the idea that impaired CDs lead to poor synchronization between sensory feedback and motor actions (Whitford et al., 2012). The nature of the impairment is unknown.

The perisaccadic localization task described above has proven to be a useful probe of the properties of oculomotor CDs. In particular, the pattern of mislocalization seen for targets flashed around the time of saccades can be used to infer the dynamics of CD signals (Schlag and Schlag-Rey, 1995; Pola, 2004). We have therefore examined CD function during saccadic eye movements in people with schizophrenia. We find that, on average, schizophrenia patients exhibit larger presaccadic and postsaccadic shifts in visual localization. These results can largely be explained by differences in the dynamics of a CD signal related to eye position.

\section{Materials and Methods}

Participants. Data were collected from 17 participants (8 with schizophrenia: 7 male, one female; 9 controls: 8 male, one female), with normal or corrected-to-normal vision. Two patients and one control were ex- 


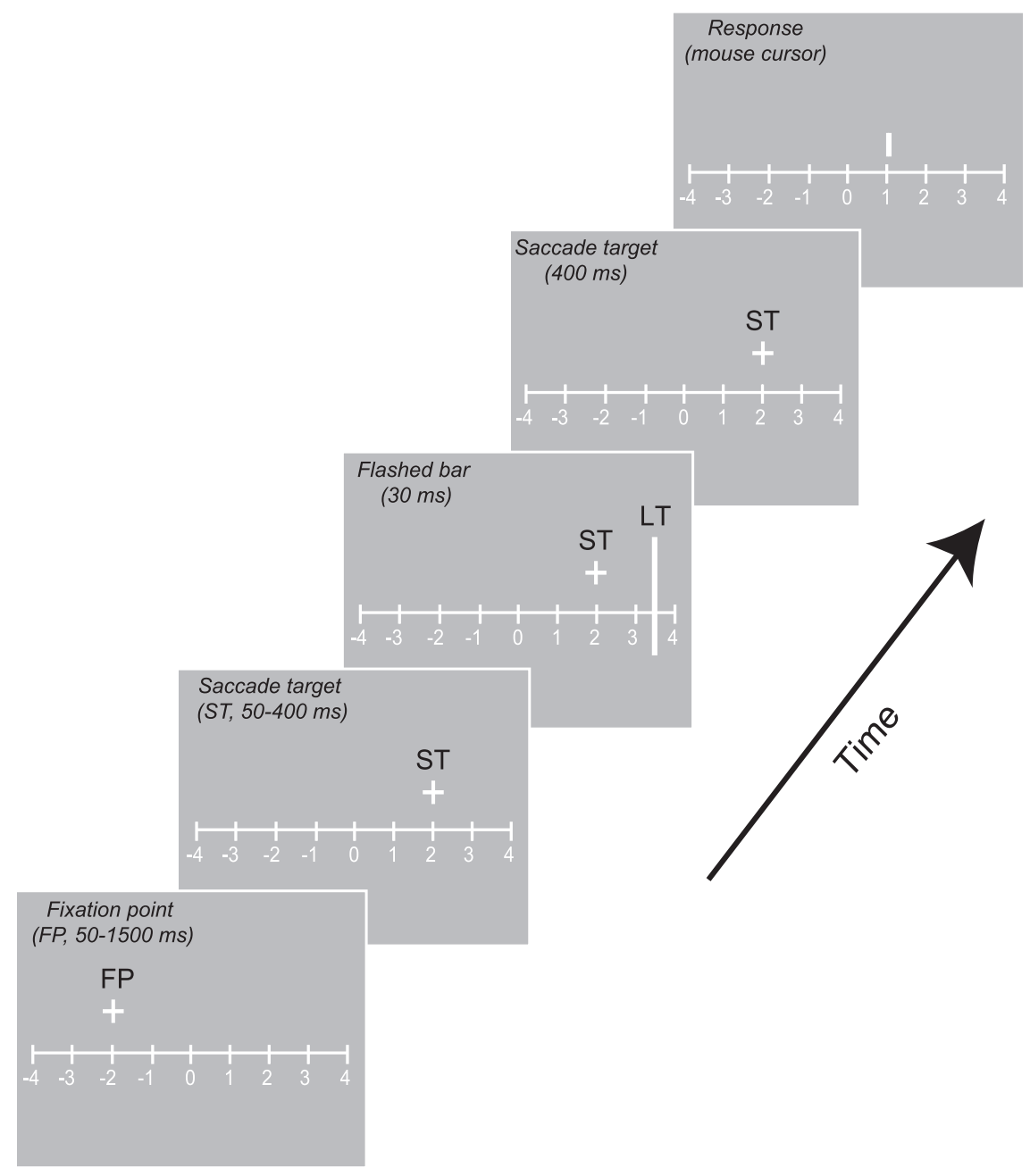

Figure 1. Sequence of events for a sample trial. After the subject acquired the FP, the ST appeared and stayed on for the remainder of the trial. After a variable delay, the localization target (LT) was flashed for $30 \mathrm{~ms}$. After successful completion of a saccade, the observer was cued to report the LT position by the appearance of a mouse cursor on the screen.

cluded for lack of quality data, leaving a total of 6 patients and 8 controls for the analyses described below. Informed consent was obtained from each participant before study participation, and study protocols were approved by the research ethics committee of the Douglas Mental Health Institute. Subjects participated in 2-4 experimental sessions, each lasting $\sim 1 \mathrm{~h}$.

All patients (recruited from an outpatient population) were clinically stable at the time of testing, and all were on a stable dose of secondgeneration antipsychotic medication $(185 \mathrm{mg} / \mathrm{d}$ chlorpromazine equivalent, CPZ). Patients and controls were excluded if they had any neurological or ophthalmologic diagnoses. They were also excluded if they had a current (i.e., $\leq 1$ year) incidence of substance abuse or alcohol dependence. There were no significant differences between patients and controls on the Wechsler Adult Intelligence Scale-Revised (Wechsler, 1981) or on the Hollingshead Occupational Scale (Hollingshead, 1975; all $p>0.05)$. However, group differences were found for years of education and the Global Assessment of Functioning Scale (all $p<0.01$ ). Symptom severity was assessed using the Brief Psychiatric Rating Scale (BPRS) (Overall and Gorham, 1962).

Stimulus design and experimental protocol. Subjects viewed a display subtending $42^{\circ} \times 28^{\circ}$ of visual angle at a distance of $61 \mathrm{~cm}$. Head stabilization was achieved with an adjustable forehead strap and chin rest. Background luminance of the display was $16.5 \mathrm{~cd} / \mathrm{m}^{2}$. Eye position was sampled at $1 \mathrm{kHz}$ using a video eye-tracker (EyeLink 1000, SR Research).

Each experimental session began with a calibration procedure (average error $<0.4^{\circ}$ of visual angle). The sequence of events in each trial is shown schematically in Figure 1. A horizontal reference ruler (luminance: $75 \mathrm{~cd} / \mathrm{m}^{2}$ ), with vertical ticks and numbers ordinally arranged at $10^{\circ}$ intervals, was present for the duration of each trial (Ross et al., 1997; Lappe et al., 2000). The beginning of each trial was marked by the presentation of a fixation point $\left(\mathrm{FP}, 1^{\circ}\right.$ in diameter) $10^{\circ}$ to the left of the screen's center. After a brief fixation period, the FP disappeared; and at the same time, a ST $\left(1^{\circ}\right.$ in diameter) appeared $10^{\circ}$ to the right of the screen's center.

At an unpredictable time (50-400 ms) after the ST appeared, a vertical bar $20^{\circ}$ in length (luminance $75 \mathrm{~cd} / \mathrm{m}^{2}$ ) was presented for $30 \mathrm{~ms}(3$ monitor frames) at one of four locations positioned symmetrically around the ST $\left( \pm 7^{\circ}\right.$, $\left.\pm 14^{\circ}\right)$. Bar presentation time ranged between $\sim-200$ and $200 \mathrm{~ms}$ relative to the onset of saccade. The successful completion of a saccade was followed by the appearance of a cursor, which subjects could move horizontally using a mouse. Subjects indicated the perceived bar location by clicking the cursor at the appropriate location. Experiments were conducted in blocks of 100200 trials, and data from all the blocks were pooled per subject. A full dataset consisted of at least 300 successful trials, defined as trials in which the final eye position was within $2^{\circ}$ of the ST.

Saccade trajectories were similar between the controls and patients. There was no significant difference in saccade latency, amplitude, or duration between the two groups (independent sample $t$ tests: $p=0.37, p=0.52$, and $p=$ 0.71 , respectively).

Data analysis. The onset and offset of saccades were determined using a variation of the method described by Carl and Gellman (1987). The start time of a saccade was calculated as the intersection between the linear regression of a data sample obtained after a velocity criterion $\left(100^{\circ} \mathrm{sec}^{-1}\right)$ was reached and the averaged eye position during the previous fixation. Trials were discarded for any of the following reasons: reaction time $>500 \mathrm{~ms}$; saccade endpoint falling outside $\pm 2^{\circ}$ of the ST; blink occurring around the time of bar presentation; and saccade occurring before target onset. On average, $3 \%$ of all trials were discarded per experiment.

We used the compression index (CI) and shift index (SI), initially proposed by Lappe et al. (2000), to quantify the magnitude of perisaccadic localization errors. The CI was calculated as the SD of the bar perceived positions, normalized to the average SD during the periods 150-200 ms after the saccade. According to this metric, a CI value of 1 denotes no mislocalization, whereas a value of 0 denotes maximal compression, which would occur if all bars were perceived at the same position in space. The SI is taken as the mean of the perceived bar positions, with the average value for each bar from 150 to $200 \mathrm{~ms}$ after the saccade subtracted from the baseline. We quantified the amount of perisaccadic perceptual mislocalization for each subject as the difference between the peak and the trough of the SI in a $100 \mathrm{~ms}$ window centered on saccade onset (Fig. 2C). Intergroup statistical comparisons were performed with independent sample $t$ tests.

Model. Perisaccadic perceptual shifts are traditionally modeled by assuming that observers estimate their eye position at the time of the bar flash (Schlag and Schlag-Rey, 1995; Pola, 2004; Teichert et al., 2010). If this information can be recovered, then the estimated location of the bar on the screen is simply the estimated eye position added to the retinal position of the bar. Following Pola (2004), we can predict the pattern of 
mislocalization from the temporal overlap between the sensory signal $R$ and the CD $C$ as follows:

$$
P=\int_{t_{1}}^{t_{2}} R(t) C(t) d t
$$

The integration limits correspond to the duration of the retinal response. For a brief flash, $R$ can persist for tens of milliseconds; $C$ is a damped (i.e., smoothed) version of the actual eye position. Mislocalization is proportional to the difference between $P$ and the actual eye position, calculated at various times relative to saccade onset (Pola, 2004; Teichert et al., 2010).

We fit the model to each observer's perisaccadic shift data, using 5 free parameters: the latencies associated with the retinal and $\mathrm{CD}$ pathways, the damping of the CD signal, and the shape and scale of the retinal response, which was characterized as a gamma distribution (Teichert et al., 2010). The damping was achieved by convolving each subject's actual eye position trace with a boxcar filter, the width of which was adjusted to fit the data. All parameters, except the CD latency, were constrained to be positive. Perisaccadic shift data were fit by minimizing the mean squared difference between the model and the data. An example model fit is shown in Figure $2 C$ (dashed line).

\section{Results}

Perceptual mislocalization of visual stimuli in patients and in controls

Figure $2 A$ shows representative data, aligned to saccade onset, from one patient with schizophrenia, based on performance of the localization task. Each data point indicates the perceived position of a flashed bar as a function of presentation time on a given trial, whereas the hatched black line indicates the position of the ST. On each trial, the bar appeared in one of four randomly chosen locations, which are assigned to different colors in the figure.

Consistent with previous findings (Ross et al., 1997; Lappe et al., 2000), there was a systematic mislocalization of the bars that began $\sim 50 \mathrm{~ms}$ before saccade onset and continued throughout the saccade. The largest errors were generally in the direction of the saccade for bars located between the fovea and the saccade endpoint (red and blue lines), and in the opposite direction for bars on the peripheral side of the saccade endpoint (green and black lines). These effects are the result, at least in part, of a CD signal, as they do not occur for identical retinal stimulation in the absence of an eye movement (Morrone et al., 1997).

The tendency to perceive the bars as nearer the ST than they actually are is called perisaccadic compression. This ef-
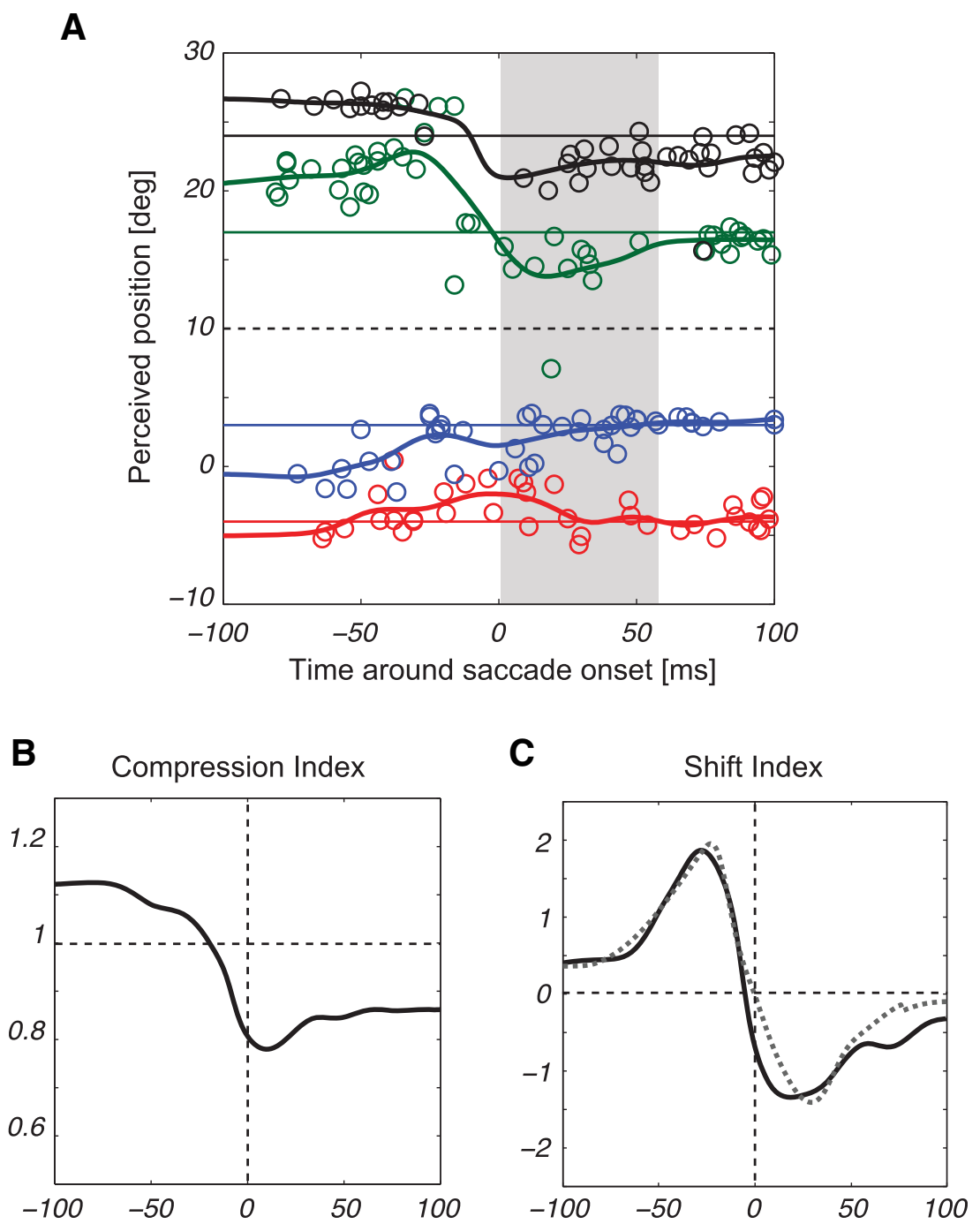

Time around saccade onset [ms]

Figure 2. Representative data. Perceived positions of a briefly flashed bar are plotted with respect to saccade onset, shown here for a representative patient $(\boldsymbol{A})$. The black hatched line in each plot indicates the ST position, and the gray area represents the average saccade duration ( $55 \mathrm{~ms}$ ). Data points (each color indicating a different bar position) represent responses for the four bar positions. Position lines were calculated as running averages for each bar position, smoothed with a Gaussian filter ( $\sigma=10 \mathrm{~ms})$. Compression $(\boldsymbol{B})$ and shift $(\boldsymbol{C})$ indices are shown for the participant in $\boldsymbol{A}$, where the gray dashed line in $C$ indicates the CD recovered by the model.
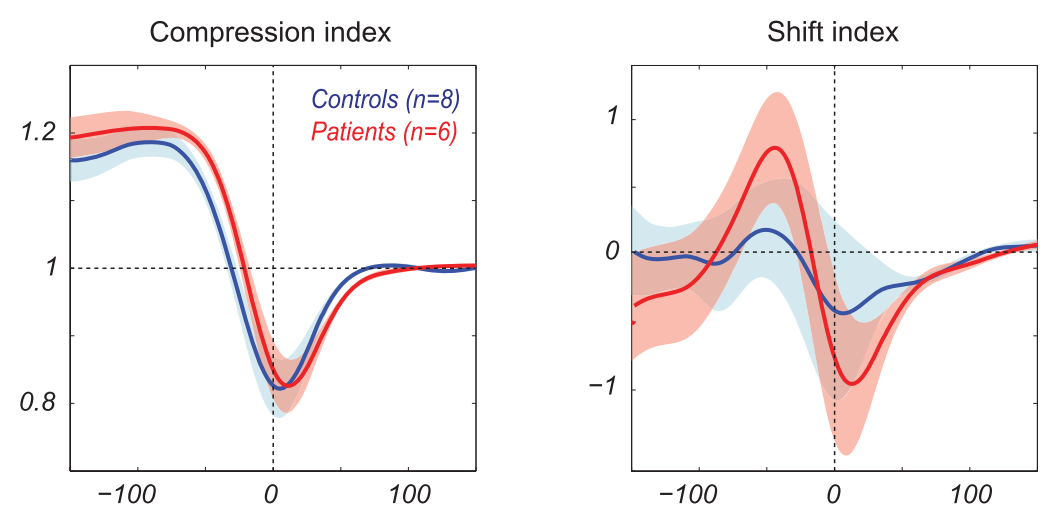

Time around saccade onset [ms]

Figure 3. Measures of perisaccadic mislocalization. Mean ( \pm SEM) compression (left) and shift (right) indices for patients (red, $n=6$ ) and controls (blue, $n=8$ ). 
fect can be quantified using the CI (Lappe et al., 2000), which calculates the $\mathrm{SD}$ across perceived bar positions at a single point in time; small values of the $\mathrm{CI}$ indicate large compression. A complementary measure of mislocalization is the SI, which is simply the mean perceived bar position at a point in time. The SI can take positive or negative values, depending on whether the bars in aggregate are mislocalized in the direction of the saccade or in the opposite direction. Both indices are normalized to their values long after the saccade, when perception is assumed to be veridical (Lappe et al., 2000).

Figure $2 B$ shows the $C I$ through time for the example subject. Consistent with previous studies, the CI begins to decrease before saccade onset, at which point it reaches a trough, and then begins to return to a value near 1 (veridical perception). Figure $2 C$ shows the SI for the same subject. Again, consistent with previous work (Schlag and Schlag-Rey, 1995), the SI shows a presaccadic increase, followed by a decrease.

Figure 3 shows the means of the compression and shift indices across patients (red) and age-matched controls (blue). On average, the CIs of the patients and controls overlap, and there is no significant difference in the peak magnitude of compression between the two subject groups $(p=0.79)$. There was a slight tendency for the $\mathrm{CI}$ in patients to lag the $\mathrm{CI}$ in controls, but this effect did not reach statistical significance ( $p=0.25$ at times of peak compression). Thus, to the extent that perisaccadic compression results from a CD signal, this signal does not appear to be impaired in schizophrenia.

By contrast, the strength of the shift effect is greater in patients than in controls. To quantify this effect, we calculated the perisaccadic modulation of perceived bar positions as the difference between the peak and trough in the shift index. These values ranged between $0.4^{\circ}$ and $2.1^{\circ}$ (mean $1.6^{\circ}$ ) for controls and between $1.6^{\circ}$ and $3.5^{\circ}$ for patients (mean $2.5^{\circ}$ ). This difference was significant $(p<0.05)$.

Previous work has shown that the presence of a visual background strongly affects perisaccadic mislocalization (Honda, 1999; Lappe et al., 2000). To determine whether this cue might account for the larger shifts seen in patients with schizophrenia, we tested 3 patients and 8 controls in additional trials in which no background was present. Consistent with previous results (Lappe et al., 2000), this manipulation largely eliminated perceptual compression in both groups. Moreover, removing the background did not increase perceptual shifts in any of the 3 patients, suggesting that differential sensitivity to this cue did not account for the observed intergroup differences.

\section{Model-based estimate of corollary discharge signals}

Perisaccadic perceptual shifts have been used previously to infer the dynamics of CD signals that encode eye position (Schlag and Schlag-Rey, 1995; Pola, 2004; Teichert et al., 2010). Common to all these approaches is the assumption that subjects localize stimuli by adding an internal estimate of eye position to the retinal location of the bar. Errors in localization then arise from the dynamics of the retinal and oculomotor signals. For instance, if the $\mathrm{CD}$ signal anticipates the actual eye position, then subjects will mislocalize bars in the direction of the saccade (Schlag and Schlag-Rey, 1995). Similarly, a visual response that lasts longer than the visual stimulus will lead to uncertainty in estimating the eye position at the time the stimulus was flashed (Pola, 2004).

To estimate possible CD dynamics underlying our perceptual findings, we fit the model of Pola (2004) to each subject's perceptual shift data, by optimizing parameters corresponding to the latency and shape of the visual response and the latency and shape
A

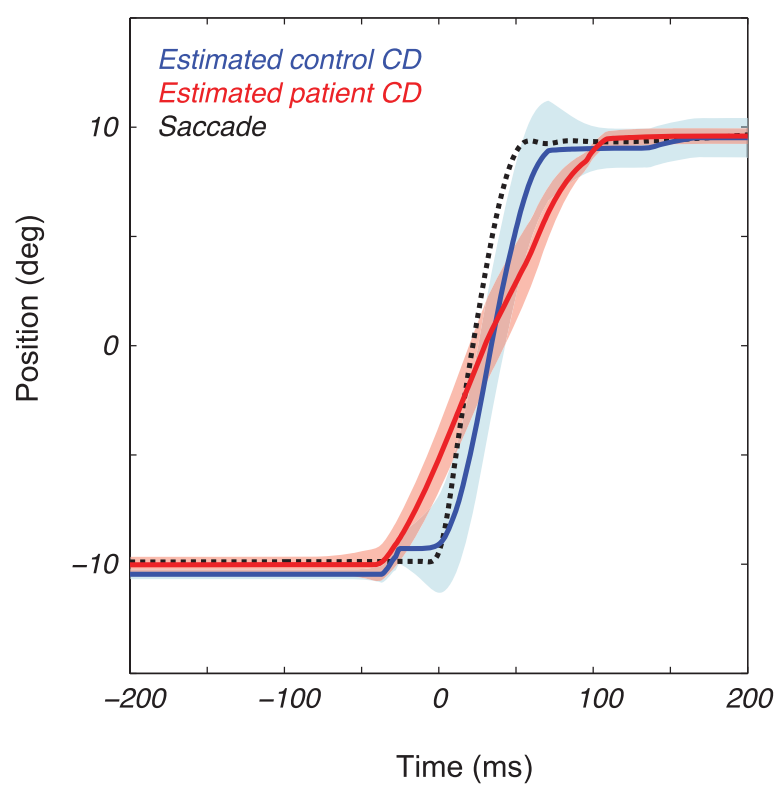

B

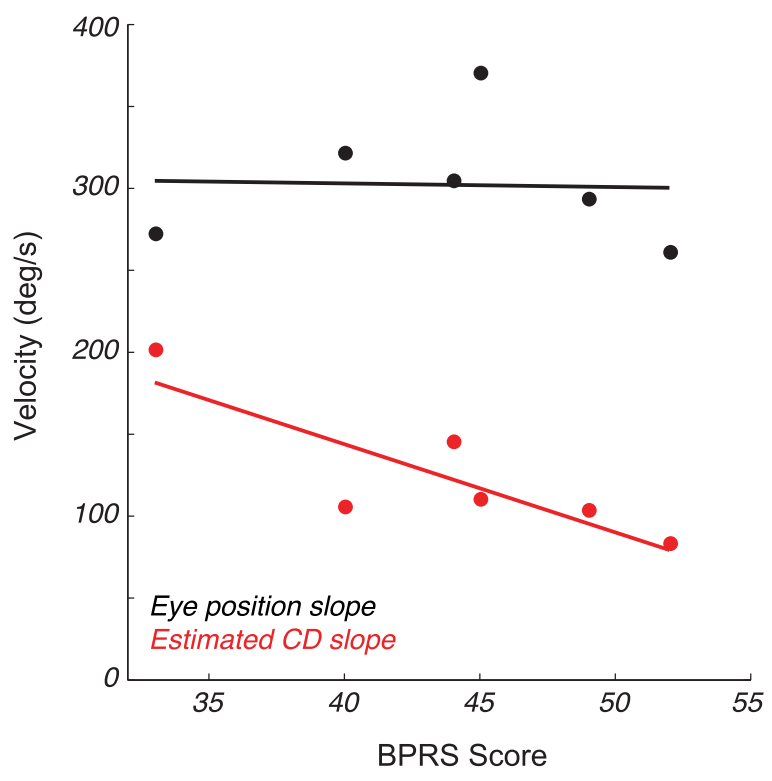

Figure 4. Modeling results. $A$, Average $20^{\circ}$ saccade (black hatched line) with overlaid CD signals (mean \pm SEM) for controls (blue) and patients (red) as recovered from the model. $\boldsymbol{B}$, The slopes of the CD (red) and mean actual eye position (black) versus patient BPRS scores (points, $n=6)$.

of the CD signal. The model fits achieved a median $R^{2}$ of 0.75 for patients and 0.68 for controls. The results indicated that the mean latency of the visual response did not differ significantly between patients and controls ( 33 vs $35 \mathrm{~ms} ; p=0.60$ ). The time course of the mean visual response was also similar for patients and controls ( $p=0.22$, shape; $p=0.84$, scale). For the CD signal, the mean latency did not differ significantly between patients and controls ( 1 vs $0 \mathrm{~ms}, p=0.57$ ). However, the damping of the CD signal was significantly greater for patients than for controls ( 93 vs $68 \mathrm{~ms}, p<0.02$ ).

Figure $4 A$ plots the mean $\mathrm{CD}$ signal recovered by the model for the patients (red) and controls (blue). Because of the larger damping parameter, the $\mathrm{CD}$ begins earlier and lasts longer in patients than in controls, leading to a shallower slope of the eye 
position $\mathrm{CD}$ through time. Interestingly, this slope was correlated with patients' scores on the BPRS (Overall and Gorham, 1962), a measure of symptom severity (Fig. $4 B$, red line; linear correlation, $p<0.03)$. This correlation was not the result of individual differences in saccade metrics, as the slope of the actual eye position was not correlated with the BPRS scores (Fig. $4 B$, black line; $p=0.9$ ).

\section{Discussion}

We examined the ability of people with schizophrenia to localize visual stimuli flashed around the time of saccadic eye movements. We found a perisaccadic compression of visual space similar to that found in healthy controls. At the same time, the overall perceptual displacement, or shift, differed significantly between patients and controls. A model-based analysis suggested that patients had an overdamped corollary discharge, and the dynamics of the signal recovered by the model were correlated with patient symptom severity. In this section, we present a mechanistic interpretation of these findings.

Much of our understanding of saccade-related CD signals comes from work in the nonhuman primate, which has revealed a pathway from the superior colliculus through the thalamus to the frontal eye fields. The information transmitted along this pathway concerns the spatial location of the intended saccade and the timing of its onset (Sommer and Wurtz, 2006). This pathway is thought to underlie the perceptual compression effects described above (Hamker et al., 2008; Richard et al., 2009). The timing of these effects is particularly relevant to the current work: a previous study has shown that perisaccadic compression is a transient phenomenon that is time-locked to gaze shift onset (Richard et al., 2011), with the duration of perceptual compression being largely unrelated to the duration of the gaze shift. This timing is similar to that of the abovementioned oculomotor CD, which consists primarily of transient bursts, rather than slowly varying signals (Sommer and Wurtz, 2004). These results are thus consistent with the idea of a CD that is unimpaired in schizophrenia and that communicates transient information about the target of an intended saccade.

Another type of oculomotor CD is a continuous readout of eye position, which reaches parietal cortex (Morris et al., 2012), likely by way of the central thalamus (Schlag and Schlag-Rey, 1984). This signal is damped relative to the actual eye position (Morris et al., 2012), in a manner that matches psychophysical data on shift mislocalization (Schlag and Schlag-Rey, 1995). Physiologically, a damped signal could result from neural noise, which tends to smooth abrupt changes in neural activity (e.g., Anderson et al., 2000). This would suggest that the eye position $\mathrm{CD}$ in people with schizophrenia is corrupted by noise, rather than being delayed or absent. Interestingly, noisy signaling of $C D$ information between cortical areas has been suggested as the neural basis of auditory hallucinations in schizophrenia (Ford et al., 2002; Ford and Mathalon, 2004).

An alternative explanation for our results is that visual stimuli are processed differently in people with schizophrenia. Indeed, the mathematical formulation of Pola's (2004) model does not distinguish between a damped CD signal and a smoothed retinal input, and there is some evidence for increased retinal persistence in people with schizophrenia (Schwartz et al., 1989). However, we suspect that differences in retinal persistence do not explain the group differences in mislocalization for three reasons. First, although the amount of damping required to fit the data leads to a reasonable approximation of the physiological CD signal (Morris et al., 2012), applying the same filtering to the retinal signal leads to a visual response that peaks at zero latency. Thus, the damping applied to the $\mathrm{CD}$ is more physiologically plausible. Second, experimental manipulations of visual persistence have little or no effect on mislocalization (Boucher et al., 2001). Finally, altered persistence would likely change the dynamics of perceptual compression (Pola, 2011), which appears to be normal in people with schizophrenia (Fig. 3). Thus, although we cannot rule out an influence of visual processing differences in people with schizophrenia, we suggest that the overdamped CD hypothesis provides a more plausible account of the data.

Overall, our results suggest that perisaccadic localization deficits in people with schizophrenia are specific to tasks that require continuous monitoring of an ongoing $\mathrm{CD}$ signal. This interpretation is consistent with findings of smooth pursuit impairments in people with schizophrenia (Holzman et al., 1973; Lindner et al., 2005; O’Driscoll and Callahan, 2008; Spering et al., 2013). In particular, these impairments are weak or absent for open-loop pursuit, which only requires an instantaneous estimate of target velocity (Spering et al., 2013). They are more profound for pursuit maintenance, which likely relies on a continuous $\mathrm{CD}$ input that conveys information about target velocity (Thaker et al., 1999). Whether these visuomotor impairments lead to functional impairments in higher-level tasks, such as reading (Whitford et al., 2013), is an intriguing question for future research.

\section{References}

Anderson JS, Lampl I, Gillespie DC, Ferster D (2000) The contribution of noise to contrast invariance of orientation tuning in cat visual cortex. Science 290:1968-1972. CrossRef Medline

Blakemore SJ, Wolpert DM, Frith CD (1998) Central cancellation of selfproduced tickle sensation. Nat Neurosci 1:635-640. CrossRef Medline

Boucher L, Groh JM, Hughes HC (2001) Afferent delays and the mislocalization of perisaccadic stimuli. Vision Res 41:2631-2644. CrossRef Medline

Carl JR, Gellman RS (1987) Human smooth pursuit: stimulus-dependent responses. J Neurophysiol 57:1446-1463. Medline

Crapse TB, Sommer MA (2008) Corollary discharge circuits in the primate brain. Curr Opin Neurobiol 18:552-557. CrossRef Medline

Feinberg I (1978) Efference copy and corollary discharge: implications for thinking and its disorders. Schizophr Bull 4:636-640. CrossRef Medline

Ford JM, Mathalon DH (2004) Electrophysiological evidence of corollary discharge dysfunction in schizophrenia during talking and thinking. J Psychiatr Res 38:37-46. CrossRef Medline

Ford JM, Mathalon DH, Whitfield S, Faustman WO, Roth WT (2002) Reduced communication between frontal and temporal lobes during talking in schizophrenia. Biol Psychiatry 51:485-492. CrossRef Medline

Hamker FH, Zirnsak M, Calow D, Lappe M (2008) The peri-saccadic perception of objects and space. PLoS Comput Biol 4:e31. CrossRef Medline

Hollingshead AA (1975) Four-factor index of social status. New Haven, CT: Yale University.

Holzman PS, Proctor LR, Hughes DW (1973) Eye-tracking patterns in schizophrenia. Science 181:179-181. CrossRef Medline

Honda H (1999) Modification of saccade-contingent visual mislocalization by the presence of a visual frame of reference. Vision Res 39:51-57. CrossRef Medline

Lappe M, Awater H, Krekelberg B (2000) Postsaccadic visual references generate presaccadic compression of space. Nature 403:892-895. CrossRef Medline

Lindner A, Thier P, Kircher TT, Haarmeier T, Leube DT (2005) Disorders of agency in schizophrenia correlate with an inability to compensate for the sensory consequences of actions. Curr Biol 15:1119-1124. CrossRef Medline

Morris AP, Kubischik M, Hoffmann KP, Krekelberg B, Bremmer F (2012) Dynamics of eye-position signals in the dorsal visual system. Curr Biol 22:173-179. CrossRef Medline

Morrone MC, Ross J, Burr DC (1997) Apparent position of visual targets during real and simulated saccadic eye movements. J Neurosci 17:79417953. Medline

O'Driscoll GA, Callahan BL (2008) Smooth pursuit in schizophrenia: a 
meta-analytic review of research since 1993. Brain Cogn 68:359-370. CrossRef Medline

Overall JE, Gorham DR (1962) The brief psychiatric rating scale. Psychol Rep 10:799-812. CrossRef

Pola J (2004) Models of the mechanism underlying perceived location of a perisaccadic flash. Vision Res 44:2799-2813. CrossRef Medline

Pola J (2011) An explanation of perisaccadic compression of visual space. Vision Res 51:424-434. CrossRef Medline

Richard A, Churan J, Guitton DE, Pack CC (2009) The geometry of perisaccadic visual perception. J Neurosci 29:10160-10170. CrossRef Medline

Richard A, Churan J, Guitton DE, Pack CC (2011) Perceptual compression of visual space during eye-head gaze shifts. J Vis 11:12.

Ross J, Morrone MC, Burr DC (1997) Compression of visual space before saccades. Nature 386:598-601. CrossRef Medline

Schlag J, Schlag-Rey M (1984) Visuomotor functions of central thalamus in monkey: II. Unit activity related to visual events, targeting, and fixation. J Neurophysiol 51:1175-1195. Medline

Schlag J, Schlag-Rey M (1995) Illusory localization of stimuli flashed in the dark before saccades. Vision Res 35:2347-2357. CrossRef Medline

Schwartz BD, Satter EK, O’Neill PT, Winstead DK (1989) Differential visual information processing between schizophrenics and other psychiatric populations. Schizophr Res 2:325-331. CrossRef Medline

Shergill SS, Samson G, Bays PM, Frith CD, Wolpert DM (2005) Evidence for sensory prediction deficits in schizophrenia. Am J Psychiatry 162:23842386. CrossRef Medline

Shergill SS, White TP, Joyce DW, Bays PM, Wolpert DM, Frith CD (2014)
Functional magnetic resonance imaging of impaired sensory prediction in schizophrenia. JAMA Psychiatry 71:28-35. CrossRef Medline

Sommer MA, Wurtz RH (2004) What the brain stem tells the frontal cortex: I. Oculomotor signals sent from superior colliculus to frontal eye field via mediodorsal thalamus. J Neurophysiol 91:1381-1402. CrossRef Medline

Sommer MA, Wurtz RH (2006) Influence of the thalamus on spatial visual processing in frontal cortex. Nature 444:374-377. CrossRef Medline

Spering M, Dias EC, Sanchez JL, Schütz AC, Javitt DC (2013) Efference copy failure during smooth pursuit eye movements in schizophrenia. J Neurosci 33:11779-11787. CrossRef Medline

Teichert T, Klingenhoefer S, Wachtler T, Bremmer F (2010) Perisaccadic mislocalization as optimal percept. J Vis 10:19. CrossRef Medline

Thaker GK, Ross DE, Buchanan RW, Adami HM, Medoff DR (1999) Smooth pursuit eye movements to extra-retinal motion signals: deficits in patients with schizophrenia. Psychiatry Res 88:209-219. CrossRef Medline

Wechsler D (1981) Manual for the Wechsler Adult Intelligence Scale-Revised. New York: Psychological Corporation.

Whitford TJ, Ford JM, Mathalon DH, Kubicki M, Shenton ME (2012) Schizophrenia, myelination, and delayed corollary discharges: a hypothesis. Schizophr Bull 38:486-494. CrossRef Medline

Whitford V, O’Driscoll GA, Pack CC, Joober R, Malla A, Titone D (2013) Reading impairments in schizophrenia relate to individual differences in phonological processing and oculomotor control: evidence from a gazecontingent moving window paradigm. J Exp Psychol Gen 142:57-75. CrossRef Medline 